\title{
La fiesta del sentido. Observaciones acerca de la esenciade la alegría a partir del pensamiento de M. Scheler, V. Jankélévitch y H. Rombach
}

\section{The celebration of meaning. Observations on the essence of happiness from M.Scheler's, $V$. Jankélévitch's and H. Rombach's thinking}

\author{
ÁNGEL E. GARRIDO-MATURANO \\ Conicet - Universidad Nacional del Nordeste, Argentina
}

Recibido: 17-06-2007 Aprobado definitivamente: 11-09-2007

Para Kasia

\section{RESUMEN}

El artículo estudia primero el paradigma religioso de Scheler, el ético de Jankélévitch y el ontológico de Rombach de la alegría, intentando en cada caso despejar los rasgos formales esenciales que definen el fenómeno en todos ellos. Redefine luego estos rasgos valiéndose de las nociones de sincronía y sintonía y muestra el trasfondo estético propio de los diferentes paradigmas de la alegría. Finalmente se refiere al enamoramiento como un modo abierto a todo hombre de experimentar la alegría en su esencia. 


\begin{abstract}
The article first deals with Scheler's religious, Jankélévitch's ethical, and Rombach's ontological paradigm on happiness, and describes the essential formal traits that define the phenomenon in the three patterns. Second, it articulates these traits by resorting to the notions of synchrony and syntony, and shows the aesthetic backgound proper to the different paradigms of happiness. Finally, the article refers to the act of falling in love as a mood open to every human being in order to experience happiness in its essential nature.
\end{abstract}

KEYWORDS

HAPPINESS, MEANING, SYNCHRONY, GRACE

\title{
I. INTRODUCCIÓN
}

LA ALEGRÍA HA SIDO OBJETO DE INTERÉS para la reflexión filosófica sólo de un modo marginal y eventual. Sin embargo, ella no anida en cualquier margen ni acompaña a cualquier evento. El margen en el que la filosofía ubicó la alegría asume el rango de frontera final. Y el evento al que se adhiere es el de la plenitud. La alegría es vista como el modo afectivo en que el hombre vivencia el acaecimiento de una plenitud final, más allá de la cual ya no tendría sentido querer ir, porque ella misma es el sentido. Ciertamente esta plenitud o perfección ha sido entendida de modos y perspectivas diversos, pero, en todo caso, la alegría nace cuando el hombre accede a una instancia de plenitud, y tanto más intensamente se la experimenta cuanto más se consuma la perfección anhelada. ${ }^{1}$ El tratamiento filosófico de la alegría resulta, pues, paradójico: es abordada de modo anecdótico y circunstancial. Pero la «anécdota» a la que se la vincula y la «circunstancia» que ella celebra no son nada más ni nada menos que la culminación o perfección suma que una cierta comprensión de la realidad puede concebir. Este artículo pretende traer al foco del análisis lo que ha permanecido en tan peculiares márgenes y mostrar que lo «anecdótico» es en verdad el desenlace del relato. Él se propone, pues, en términos generales, resaltar la jerarquía filosófica de la alegría en tanto disposición afectiva que celebra el acaecimiento pleno del sentido al que la ek-sistencia en tanto tal tiende. ${ }^{2}$

Ahora bien, la plenitud de sentido ha sido considerada desde múltiples perspectivas por el pensamiento occidental. Sería un desatino, en el marco de un ensayo como éste, breve y de carácter filosófico y no filológico, querer realizar

1 Ya Spinoza en la tercera parte de su Ética, proposición XI entiende por alegría: «una pasión por la que el espíritu pasa a una mayor perfección». Benedictus de Spinoza, Éthique. Démontrée suivant l'ordre géométrique et divisée en cinq parties, tr. francesa de C. Appuhn, París : Garnier, 1953, tomo I, p. 267.

2 Con la grafía 'ek-sistencia' se mienta aquí, el hecho de que el hombre, en cuanto es, está «esencialmente tendido hacia» aquello que considera que tiene o da sentido. Sin esta tensión hacia el sentido, la existencia misma sería impensable, estaría atrofiada o negada. 
una compilación más o menos erudita del conjunto de referencias a la alegría hechas por la filosofía a lo largo de su historia. Sin embargo, estimo que es posible -sobre todo si nos centramos en la filosofía contemporánea- abordar la cuestión desde tres paradigmas fundamentales, aunque no exclusivos ni excluyentes, de comprensión del fenómeno, correlativos a tres modos diferentes de concebir la plenitud. Ellos son el ético, el religioso y el ontológico. Hemos elegido a tres distintos pensadores contemporáneos -Max Scheler, Vladimir Jankélévitch y Heinrich Rombach-, que han tratado explícitamente la cuestión que nos ocupa, para introducirnos respectivamente a cada uno de los paradigmas mencionados. Nuestra intención no es, sin embargo, compararlos, sino reinterpretarlos de modo tal que la interpretación ponga de manifiesto los rasgos formales comunes a los tres modelos: aquellos sobre los cuales cada uno de los modelos determina su concepción específica de la alegría. Nuestro método podría ser caracterizado, entonces, como una hermenéutica trascendental destinada a despejar o explicitar «la esencia» de las diferentes concepciones paradigmáticas del fenómeno. Para ser más precisos se trata de una hermenéutica fenomenológico-trascendental en cuanto analiza la alegría no como un mero estado mental inmanente a la estructura psíquica del sujeto, sino como el resultado de una correlación fenomenológica entre un cierto modo consumado de darse lo que es y un cierto modo, también consumado, de experimentarlo. Nos guía la sospecha de que los diferentes paradigmas de alegría presuponen una dimensión estética, en cuanto lo sentido es una cierta forma particular de belleza: el acaecimiento de un instante de sintonía y sincronía integral entre el existente y lo que le es dado, que vuelve transparente o translúcido el sentido de la existencia en su conjunto. A procurar determinar formalmente la naturaleza de esta sintonía y sincronía y a mostrar hasta qué punto la alegría no constituye un estado psíquico ocasional, sino una disposición afectiva fundamental de la existencia humana, sin la cual ésta sería inconcebible, es aquello a lo que en términos concretos se orienta el presente estudio.

II. Alegría como bienaventuranza. Scheler o el paradigma Religioso De LA ALEGRÍA

Scheler da comienzo a su análisis de la alegría recordándonos que «la doctrina cristiana del sufrimiento exige más que soportar pacientemente los males». «Exige, o mejor, apunta a un padecimiento bienaventurado, y entiende, en última instancia, que sólo un hombre bienaventurado, o sea que está en el seno de Dios, puede padecer rectamente el dolor y el sufrimiento, amarlo y, si fuera necesario, ir en su búsqueda». ${ }^{3}$ En esta bienaventuranza, comprendida

3 Max Scheler, Amor y conocimiento, tr. A. Klein, Buenos Aires: Sur, 1960, p. 96. Sigla: AC. 
por Scheler como un «estar en el seno de Dios», es decir, como la efectiva experiencia o posesión de Dios en mí, cree hallar el filósofo la alegría más profunda a la que pueda aspirar un ser humano. Tan profunda que el hombre, como lo habrían hecho los mártires, es capaz de afrontar con serenidad los peores sacrificios y regocijarse en medio de los más inclementes tormentos, cuando el contacto con los «dolores de la tierra» le permite tomar mayor conciencia «de toda la amplitud de su intimísimo amparo y salvación en Dios». ${ }^{4}$ No es, entonces, el sufrimiento por el sufrimiento mismo -el mártir no es masoquista- ni por el deseo de glorificación personal -tampoco es un héroe- lo que hace que el sufriente pueda afrontar «con sentido» ${ }^{5}$ los tormentos, sino el hecho de que esos dolores constituyen una experiencia de purificación en virtud de la cual él se desentiende de los niveles periféricos de su alma y se precipita hacia lo más profundo de su espíritu. Allí, en las profundidades, el mártir se descubre amado por Dios y, consecuentemente, se despierta en él una alegría tan serena que no puede ser turbada por las borrascas superficiales del dolor.

Scheler distingue diferentes niveles afectivos en la existencia. En primer lugar estarían las zonas de las sensaciones localizadas corporalmente, como el dolor físico y la voluptuosidad: lo que solemos llamar sensaciones en sentido estricto. Luego los estados anímicos resultantes de nuestra conformación psíquica individual, a los que en su conjunto proponemos designar con la palabra psiquismo. Y, finalmente, un yo espiritual profundo o íntimo, que sería factible denominar ipseidad, en el cual el sujeto no se afecta (voz media), sino que ya siempre y a su pesar está o se encuentra autoafectado (voz estrictamente pasiva) por el pathos de la alegría o del dolor de experimentarse a sí mismo como amado o no por Dios. ${ }^{6}$ Cada uno de estos niveles afectivos está determinado por su propia legalidad y es independiente respecto del orden imperante en los otros niveles. Así es perfectamente posible, según Scheler, que al mismo tiempo distintos estratos se hallen movidos por afecciones de signo diverso. Por ejemplo, es factible disfrutar el buen sabor de una comida, pero, de modo independiente y concomitante, sentir en un plano más íntimo que ni esa comida, ni los comensales que nos rodean, ni la existencia en su conjunto tiene sentido; y desesperar por la falta de asidero de nuestra vida y lo vano de nuestros placeres. Este sería el caso del hedonista, que, tras su búsqueda ansiosa de placeres, esconde, para Scheler, siempre un desventurado. Ahora bien, lo propio de los afectos más profundos, como la verdadera alegría surgida del experimentarse amado por Dios ahora mismo (incluso cuando ese ahora es un ahora de dolor

4 Ibid.

5 Cf. AC, p. 97.

6 Esta designación de la alegría como pathos autoafectivo la tomo de R. Kühn, Geburt in Gott. Religión, Metaphysik, Mystik und Phänomenologie, Freiburg: Alber, 2003, p. 75. 
para los estratos afectivos más superficiales), radica, como lo adelantábamos al situar el fenómeno en el dominio de la ipseidad, en hallarse sustraídos a la voluntad y a la intención consciente. Propiamente hablando no nos ponemos alegres, sino que la alegría nos brota. Dicho en términos religiosos: los sentimientos más profundos -y específicamente la alegría-, «adquieren un carácter cada vez más pronunciado de gracia». ${ }^{7}$ Y la alegría «es tanto más 'profunda' y tanto más indestructible por el destino exterior, cuanto mayor sea el carácter de gracia con que brota de nuestro yo-mismo más central o íntimo». ${ }^{8}$ Es decir, cuanto más intensamente brote de la ipseidad del existente el sentimiento de alegría o bienaventuranza, tanto más capaz se vuelve de sobrellevar el sufrimiento en los niveles periféricos, pues esta bienaventuranza íntima determina el modo en que el hombre encara el conjunto de sus posibilidades. Por ello el hombre verdaderamente alegre no sólo no huirá del dolor ni de la privación de los placeres superficiales, sino que incluso buscará «con sentido» este dolor, si él contribuye, a modo de catarsis, a experimentar en plenitud la gracia sita en su ipseidad. La alegría no es, entonces, un fin o meta que uno busque por medio de la obtención de un placer determinado. Scheler rechaza todo eudemonismo de metas. Ella es, por el contrario, el correlato o «fenómeno concomitante $»^{9}$ que brota por sí mismo cuando el bienaventurado experimenta la gracia de saberse tal, esto es, de saber que su vida es infinitamente amada por un ser infinitamente poderoso, cuyo amor no puede ser borrado por los sufrimientos y cuyo poder es mayor que el de la misma muerte.

Si procuramos reinterpretar en términos filosóficos ${ }^{10}$ esta concepción religiosa de la alegría, tenemos que llamar la atención sobre tres notas que el análisis de Scheler pone de manifiesto y que me parecen comunes a toda forma de la alegría: su carácter de pathos autoafectivo o gracia, su vínculo con la noción de sentido, y el hecho de que en ella se transluzca una composibilidad vital. En lo que al primer punto respecta, digamos que, a diferencia de los demás placeres, la alegría no puede ser buscada intencionalmente, como tampoco es posible evitarla. La alegría, que en el caso del paradigma religioso está dada por la posesión

7 Ibid.

8 Ibid.

9 AC, p. 107.

10 Se me permitirá aquí una disquisición metodológica que no creo irrelevante. Términos filosóficos significa tanto como términos universales. Tratar de expresar filosóficamente qué es la alegría implica tratar de poner de manifiesto las notas esenciales que caracterizan ese afecto y que se translucen no sólo en el modelo religioso, sino en los otros modelos no religiosos de experiencia de la alegría. En otras palabras: lo que nos interesa no es el carácter estrictamente religioso del contenido de la alegría scheleriana, sino la forma que asume ese afecto y que ciertamente se transluce en el ejemplo de la alegría religiosa de la que Scheler habla, pero que es común a toda manifestación humana de alegría. 
o no de Dios en lo íntimo del alma, acaece. La alegría nos sobreviene o, para decirlo fenomenológicamente, nos encontramos autoafectados por el pathos de la alegría. Todo intento de alcanzarla o proyectarla la paraliza. Si la alegría nos lleva a poder soportar los «dolores periféricos», ello se debe a que impregna la totalidad de nuestra existencia, se impone por sobre los demás afectos e inunda integralmente nuestro «ser-en-el mundo». La relación con la alegría bien podría ser calificada como un no poder evitar que todas las dimensiones de nuestro existir y de nuestras relaciones con el mundo, más allá del carácter específico que revistan cada una de ellas por separado, se hallen inundadas por la alegría. Ahora bien, toda meta buscada o proyectada espontáneamente es un objeto de la voluntad y, en tanto objeto, es de-terminado y parcial. Lo buscado es «algo» que, como «algo» que es, se diferencia de otros «algos». Y ese algo objetivo no puede ser nunca el motivo de alegría -a lo sumo lo será de un contento particular-, porque la alegría surge como correlato no de nuestra relación con algo, sino con la totalidad de nuestra existencia. La alegría, por lo tanto, no puede ser buscada, sino que le sobreviene al o inunda el conjunto de nuestra existencia entera. Y su motivo, aquello de lo que ella es correlato, no puede ser definido en términos objetivos, como no puede ser definido en términos objetivos por Scheler esto de «poseer efectivamente a Dios en el seno del alma». Ella, a diferencia de otras sensaciones de placer, no resulta de un objeto determinado, de ningún «algo», sino que es el correlato de un acaecimiento que da sentido al conjunto de todos los algos de la existencia. Desembocamos, así, en la segunda nota de las tres que anunciábamos antes. La alegría es el correlato afectivo propio del acaecimiento de la experiencia efectiva de la plenitud del sentido. Así, en el paradigma religioso de Scheler, la gracia de poseer efectivamente a Dios en el alma, de la cual la alegría brota, es una experiencia del sentido, ya que constituye la realidad última a partir de la cual el hombre religioso encara la totalidad de su existencia. Ahora bien, ¿en qué radica ese sentido? Con esta pregunta avanzamos sobre la tercera y última nota. Sin embargo, la pregunta es en sí capciosa porque el sentido, en tanto no es un algo objetivo, es indefinible en su contenido concreto. Su acaecimiento es distinto para cada existente, pues la existencia de cada hombre es en cada caso una totalidad diferente. Sin embargo, podemos reparar en una de las características formales que asume esta experiencia del sentido y que el modelo religioso también trasunta: la composibilidad vital. Si la alegría es el correlato afectivo del acaecimiento de un sentido existencial integral, y si la existencia es ser en el mundo con lo otro y los otros, entonces la alegría es la expresión afectiva de hallarse en una relación armónica con el conjunto de la realidad. Dicho más precisamente, una característica formal de la alegría está dada por el hecho de que, en el instante de alegría profunda, sentimos que el despliegue de nuestras posibilidades vitales está en consonancia con el conjunto de posibilidades vitales de aquella realidad que constituye 
nuestro horizonte. Así el mártir, poseído de alegría profunda, ni experimenta su martirio como un sinsentido en el conjunto de la realidad ni se regocija del dolor por vulgar masoquismo. Por el contrario, esa posibilidad vital que es el martirio se com-pone con el conjunto de posibilidades de la realidad toda y renueva tanto al mártir como a la realidad. En efecto, por un lado la realidad de esa época necesitaba testigos (estos es precisamente lo que significa el término mártires) para que la verdadera vida, a saber, la vida que se siente a sí misma como don de Dios y que, por ello, experimenta ya en sí misma la eternidad y la plenitud, pudiera fortalecerse y expandirse entre los hombres, y, de ese modo, la humanidad renaciera «en Cristo». Y, por otro lado, los mártires necesitaban purificarse por medio del dolor que la realidad les imponía para experimentar en plenitud «la efectiva posesión de Dios en el seno del alma» y renacer como bienaventurados del Reino de los Cielos. La alegría religiosa, que Scheler encuentra por excelencia en los mártires, ${ }^{11}$ muestra, pues, también que el instante de alegría que sentimos (y no podemos no sentir) expresa el estar nuestra vida efectiva en una armonía nueva con el conjunto de la vida. Y lo pone de manifiesto de un modo extremo, pues la posibilidad vital a través de la cual el mártir encuentra sentido a su existencia y se siente en armonía con lo otro y con los otros, es precisamente el sacrificio de su vida. Aquí no nos interesa juzgar-cosa por lo demás imposible- si realmente el martirio conduce al fortalecimiento de la fe y al renacimiento en Cristo, ni si el mártir experimenta a Dios en sí a través del martirio. Lo que nos interesa es destacar este rasgo formal propio de la alegría, que se trasunta también en esa concresión especial suya que es la bienaventuranza religiosa, a saber, el hallarse en conexión vital armónica con todas las cosas. Dicho de otro modo, el sentir por un instante -el instante de alegría- que lo que nos acaece le brinda sentido al conjunto de nuestra vida, y que, correlativamente, nuestra vida, en tanto determinada por ese sentido, está en consonancia con el sentido de la vida en su conjunto: se justifica.

Pero no sólo por vía religiosa se alegra el hombre.

\section{Alegría COMO REDENCIÓN. JANKÉLÉVITCH O EL PARADIGMA ÉTICO DE LA ALEGRÍA}

El pensador francés Vladimir Jankélévitch identifica la alegría con el correlato afectivo de un particular estado de la conciencia moral, que podríamos denominar «conciencia redimida». Esta redención acaece, paradójicamente, a través de la «mala conciencia» del mal cometido, esto es, a través de lo que usualmente llamamos remordimientos de conciencia. Escribe Jankélévitch:

$11 C f . A C$, p. 96. 
«La mala conciencia del mal es un bien [...], si ella es sincera, es decir, sin complacencia; la conciencia de la falta redime misteriosamente la falta [...] a condición de que ella no sea conciencia expresa para redimir esta falta o de que no se vea en la vergüienza un medio para liberarse de ella [...]». ${ }^{12}$ Para el filósofo, los remordimientos nos redimen de la culpa siempre y cuando sean categóricos y desinteresados, es decir, cuando se los tenga por sí mismos y no como medio expreso y consciente para luego obtener el derecho a autoperdonarse. La mala conciencia es, entonces, un «beneficio doloroso», pero la buena conciencia de la mala conciencia, esto es, la conciencia de la presunta bondad de la mala conciencia, la transforma en una pose, en un «ardid diabólico del ego» que encuentra a través de ella un medio para autocompadecerse y autojustificarse. La pureza de la conciencia del mal cometido, la pureza relativa de la impureza, «es permanecer siendo sincera y dolorosamente mala conciencia del mal movimiento y ameritar así un perdón que ella no ha buscado». ${ }^{13} \mathrm{Y}$ la impureza de la impureza es convertirse en «buena conciencia» de la mala conciencia, porque de ese modo a la mala intención de la falta se le suma la mala intención de la autocomplacencia.

Ahora bien, la «buena conciencia» de la mala conciencia tiene un correlato afectivo determinado, a saber, la autosatisfacción o «satisfacción estática», en tanto en ella el yo sólo se relaciona con sí mismo y nunca se mueve verdaderamente hacia el otro. Jankélévitch no duda cuando de lo que se trata es de poner nombre propio a este sentimiento de autosatisfacción: lo llama «contentamiento burgués». ${ }^{14} \mathrm{Del} \mathrm{mismo} \mathrm{modo} \mathrm{la} \mathrm{mala} \mathrm{conciencia} \mathrm{sincera} \mathrm{y} \mathrm{desinteresada,} \mathrm{que} \mathrm{no}$ esconde ninguna buena conciencia detrás de sí, tiene su propio correlato afectivo. Y este es, precisamente, la alegría. En efecto, si la impureza de la buena conciencia, empotrada en su propio interés, engendra el contento burgués, cómo -se pregunta el filósofo- la catarsis que obra la sincera mala conciencia y que es «con-versión al otro y transfiguración de un yo purificado de todo 'auto' no nos procuraría la embriaguez de la alegría». ${ }^{15}$ Jankélévitch en su análisis de este sentimiento de alegría, concebida en términos éticos, hace hincapié en un aspecto formal del fenómeno que también estaba presente en el paradigma religioso: la alegría profunda es el correlato de una conciencia naciente -la conciencia redimida-y, en tanto tal, le es inherente un renacimiento y una recreación. Así como el hombre religioso renace alegremente en Cristo cuando descubre la posesión de Dios en el seno del alma, así también el hombre purificado por el

12 Vladimir Jankélévitch, La mauvaise consciente, París: Aubier-Montaigne, 1966, p. 206. Sigla: $M C$.

13 MC, pp. 207-208.

14 Cf. MC, p. 209.

15 Ibid. 
remordimiento sincero puede liberarse de la culpa y comenzar con alegría de nuevo consigo mismo. Y así como el religioso, que ha experimentado a Dios en su alma, recrea su relación con el mundo y el mundo a través de esta nueva relación con él, así también el hombre purificado por el remordimiento sincero restablece nuevos lazos con los otros y con las cosas y encuentra un nuevo sentido para su existencia. Este vínculo entre alegría y renovación del propio ser en el mundo lo mueve a Jankélévitch a afirmar que la alegría celebra la «fiesta de la creación». ${ }^{16} \mathrm{Y}$ no le falta razón para afirmarlo, pues ella se da en el instante y en el lugar en los que se celebra el nacimiento de un hombre enteramente nuevo, es decir, de un hombre que ha encontrado un nuevo sentido a su existencia hasta entonces culpable, y, consecuentemente, se celebra también la creación de un orden enteramente nuevo, de un nuevo modo de vincularse con el mundo. En efecto, cuando el hombre, sin buscarlo previamente, se encuentra ${ }^{17}$ con que se halla en paz consigo mismo, purificado y liberado de los remordimientos esenciales que paralizaban su existencia, entonces a todo él lo invade una alegría profunda: se desbloquea su conciencia entumecida y puede recomenzar con su vida y encarar desde otro trasfondo, esto es, con un nuevo sentido, su futuro. La alegría, así concebida, ${ }^{18}$ es el correlato de la apertura de nuevos horizontes. Y la apertura de nuevos horizontes desgarra nuestra desesperación y culpa, que nos mantenían estacionarios en nosotros mismos, y, yendo más allá de la autosatisfacción burguesa, igualmente inmóvil, nos revincula con el otro y con la esperanza.

En la concepción de Jankélévitch volvemos a encontrar los mismos rasgos formales de la alegría entrevistos cuando tratamos el paradigma religioso, pero enriquecidos por el énfasis que el autor pone en el aspecto de recreación, de apertura de nuevos horizontes y, por tanto, de una nueva esperanza, concomitante con la redención moral que la alegría celebra. Así, por ejemplo, la relación existente entre alegría y composibilidad vital se ve reflejada en la idea de un «orden totalmente otro» al que ingresa el redimido por la «mala conciencia» del mal cometido. Se trata de un nuevo orden, en cuanto restablece el conjunto de sus relaciones con los otros de un modo tal que esas relaciones respeten la alteridad del otro y, por tanto, sean armónicas con las posibilidades vitales del otro. Pero se trata, además, no sólo de un orden, sino de un orden nuevo: la redención nos abre insospechadas posibilidades de relación con los otros que estaban bloqueadas tanto en el caso del burgués conforme y contento con su

16 Ibid.

17 Encuentro que puede asumir la forma del perdón que el otro me concede o del perdonarse a sí mismo que no surge de la autocomplacencia, sino que brota por sí mismo e inconscientemente desde el propio espíritu.

18 Es decir, en el sentido de laetitia y no de gaudium. 
buena conciencia, que sólo se satisface consigo mismo y nunca se vierte al otro, como en el del preso de remordimientos, que se encuentra enclaustrado en su culpa. Pero si este orden nuevo es posible, ello se debe a que la alegría celebra el hecho de que el redimido ha encontrado una paz sincera, es decir, no buscada de antemano, sino precisamente encontrada, y sobre la base de esa paz encara y re-configura su existencia toda, la cual adquiere así un nuevo sentido. La alegría moral es precisamente el correlato afectivo de la liberación de los remordimientos y de las hipocresías y de la consecuente posibilidad de salir del encierro en sí y proyectarse hacia un nuevo horizonte. En cuanto el futuro y el horizonte hacia el que nos proyectamos conforman el sentido del existir en su conjunto, también la alegría moral celebra el sentido. Y, finalmente, en cuanto la paz y la liberación que la alegría moral festeja es, como decíamos recién, estrictamente encontrada y no buscada ella es una gracia que le acaece al sujeto. Jankélévitch lo dice expresamente: «El remordimiento no es el purgatorio progresivo de nuestras impurezas, [...]: él es el pasado de desesperanza que su sinceridad misma, como por el efecto de una gracia, transfigura o metamorfosea repentinamente en presente de alegría». ${ }^{19}$ Una gracia que, como el sueño, se aleja en cuanto se lo busca. ${ }^{20}$

Pero no sólo por vía ética se alegra el hombre.

\section{Alegrí́a COMO Iluminación. Rombach o el PARAdigma ontológico de LA ALEGRÍA}

De los distintos modelos o modos de manifestación de la alegría que aquí estamos analizando es, tal vez, el de Heinrich Rombach, creador de la «ontología estructural», el que más ha avanzado en la determinación formal del fenómeno. Pero el tratamiento de la idea de alegría que Rombach propone requiere inevitablemente recordar algunos principios básicos de su obra capital: la Strukturanthropologie, ${ }^{21}$ en especial la noción central de situación.

La situación forma parte de lo que Rombach llama fenómenos fundamentales, es decir, es un fenómeno que se da por sí mismo y que no puede ser comprendido como derivación de otro. Podría caracterizársela como aquello en donde ya siempre se encuentra existiendo un hombre concreto. Rombach la

$19 M C$, p.213. Cursivas mías.

20 Cf. MC, p. 210.

21 Heinrich Rombach sentó las bases de su ontología estructural en su obra Strukturontologie. Eine Phänomenologie der Freiheit, Freiburg/München: Alber, 1971. Sin embargo, su obra capital, aquella en la que despliega sistemáticamente en toda su profundidad el conjunto de su pensamiento, es su Strukturanthropologie. Der menschliche Mensch, Freiburg/München: Alber, 1987. Sigla: SA. 
define en los siguientes términos: «La situación no es simplemente lo que me rodea, sino lo que me concierne [de antemano]».22 Todas aquellas estructuras, es decir, configuraciones de sentido, que me atañen, de modo tal que yo no puedo eludirlas sin que esa elusión sea ya un modo de integrarme en ellas, forma el ámbito de concernencia o espacio situacional del existente. La concernencia (Betreff) se da con antecedencia (Vorgängigkeit) a todo comportamiento mío respecto de lo que me concierne, y me muestra ya siempre las cosas y la correlación entre ellas en una cierta dirección (Gerichtetheit). En otros términos: con situación Rombach mienta el acaecerme del mundo orientado hacia un determinado modo de patencia y, consecuentemente, hacia una cierta configuración estructural. Por ello puede escribir el filósofo que «la diversidad de orientaciones en que las cosas se revelan configura el espacio estructural de la situación».23 Concernencia y antecedencia no propiedades de las cosas que se revelan en la situación, sino que son las propiedades esenciales de la situación misma. Ambas propiedades son conjugadas por Rombach en el término Voreingenommenheit (estado-de-tomado-de-antemano). Aquello que me toma de antemano y que inevitablemente me concierne y orienta en una cierta dirección hasta el punto de que yo no soy sino el modo en que asumo y me integro en ese ámbito de concernencia, es la situación. Esta concepción de Rombach de la situación determina paralelamente su noción de identidad o, propiamente hablando, de idemidad. El yo no es ningún núcleo substancial ni una conciencia intencional. Nuestro yo interior (Innen) está constituido por la situación y no es más que el acaecer de un estado-de-dado del mundo en una configuración situacional de interrelaciones. «Nosotros somos la situación». ${ }^{24}$ Pero no lo somos en el sentido activo de identi-ficarnos con ella, sino en el sentido pasivo de estar idemizados con ella, esto es, de ser una misma cosa (idemidad) nuestro «sí mismo» y la emergencia a través nuestro del conjunto de situaciones que nos concierne. Ahora bien, las situaciones, para Rombach, no se dan caótica, sino articuladamente. Cada situación se perfila siempre como situación interior rodeada de una exterior que la abarca y la concierne, y así sucesivamente. El yo, en tanto situación más interior, concernida por las situaciones exteriores, es el núcleo de los diversos anillos situacionales, ilustrados por Rombach con la figura de una serie de circunferencias concéntricas. En la serie cada situación es a su vez interior y exterior. Como interior es lo concernido, como exterior lo concerniente. Entre más indeterminada es la concernencia de una situación tanto más lejana y de mayor alcance es ella, y tanto menos conscientes somos de su influencia. Y la totalidad de las situaciones se halla, a su vez, rodeada y concernida por la 
situación extrema que no es otra que el Todo-Vida (All-Leben). ${ }^{25}$ Este Todo-Vida, que todo lo abarca, no es ninguna situación determinada, sino el principio vital (que está presente en todas las situaciones y actúa en ellas, en la medida en que les confiere vida, esto es, les in-funde el constante impulso de constituirse y reconstituirse estructuralmente en busca de generar conjuntamente un auténtico cosmos. Este principio que vincula armónicamente a todo con todo y que a todo vitaliza tiene múltiples nombres: uno de ellos es, para Rombach, Dios.

Pues bien, para el autor, en la relaciones de movilidad entre los distintos anillos situacionales que conforman la serie concéntrica se encuentra el origen y la determinación de los temples afectivos fundamentales. Por tales ha de entenderse aquellos temples que son ontológicamente constitutivos de la existencia, en tanto son esenciales a la movilidad interna dentro del espacio situacional. La alegría específicamente emerge cuando las relaciones de movilidad entre los múltiples estratos que conforman el conjunto del espacio situacional que el yo es se da con una dinámica tal que resulta posible el tránsito libre y fluido entre todos ellos, desde los más cercanos a los más lejanos y viceversa; y, concomitantemente, resulta posible experimentar la coordinación estructural que los vincula y vivifica. Por experiencia de la coordinación estructural de los estratos habrá que entender una interpretación que los atraviese $\operatorname{todos}^{26}$ y los comprenda no como estados fijos de cosas, sino como un proceso integral y dinámico de autoconfiguración de la vida. En cuanto más intensamente experimenta el existente que la vida, entendida como impulso de autoconfiguracion que recorre la realidad toda, traspasa y vincula el conjunto de las situaciones que él es, tanto más intensa es su alegría. Por ello puede afirmar Rombach que, como temple afectivo fundamental, la alegría no tiene una causa psicológica ocasional y concreta. «La causa es la composición situacional del todo de la existencia en la relación mutua de sus estratos interpretativos». ${ }^{27}$

Como es posible advertir, el modelo de Rombach es, precisamente, de naturaleza ontológica. La alegría no es propiamente concebida como un estado anímico subjetivo en el sentido psicológico del término, sino que ella, como temple fundamental, sucede cuando lo que es se da, a través de una totalidad situacional idémica con el yo, con una movilidad tal que se transparenta el «ser» de lo que es, esto es, aquello que hace ser a lo que es y que lo hace ser así como es, a saber: el impulso vital de autoconfiguración estructural que recorre la realidad toda. Ya en este punto de nuestra reconstrucción del modelo ontológico, podemos advertir claramente dos de las notas que caracterizaban a los modelos anteriores. La alegría es un pathos autoafectivo o gracia recibi- 
da por el sujeto. El todo situacional, toda vez que constituye el «el estado de tomado de antemano» del existente, se le da o le acaece al yo, a través de los diferentes estratos con los que ese yo se idemiza, de modo tal que le sea posible experimentar la vitalidad que lo recorre. En tanto tal el sujeto se encuentra con la alegría y no puede buscarla a través de causas particulares. Con más claridad aún se advierte que la alegría es, también para Rombach, el correlato afectivo de una experiencia de composibilidad vital. En efecto, la alegría nos muestra la coordinación estructural del mundo abriéndose en el conjunto de situaciones que un yo es. Pero, ¿qué pasa con la cuestión del sentido? Rombach es quizá quien con más agudeza puso de manifiesto el vínculo entre sentido y alegría, pero, para comprender en detalle este vínculo, es menester profundizar en nuestro análisis del modelo.

Decíamos más arriba que la situación extrema -el Todo-Vida- no es ningún estado de cosas delimitado ni objetivable. Por eso ella no puede ser conocida ni designada (es «nada»), pero sí puede ser experimentada, de un modo en cada caso determinado, ${ }^{28}$ es decir, siempre sólo en un respectivo camino. Desde el punto de vista formal lo propio de este camino radica en mostrar que en cada caso de manera distinta la situación extrema interviene en todas las otras situaciones, hasta llegar a la más interior de los anillos concéntricos, y que, en virtud de dicha intervención, se genera un vínculo concreto que abarca hasta los más ínfimos detalles de cada situación y que puede caracterizarse como un impulso de autoconfiguración estructural de la vida en el todo situacional. A quien es capaz de experimentar esta situación extrema inter-viniendo a través de todos los anillos situacionales concéntricos, es decir, a quien puede experimentar el «camino de la vida», lo llama Rombach un iluminado (Erleuchtete). El iluminado se mueve de tal modo que todas las situaciones cercanas y medias se vuelven patentes para él en la luz y la claridad de la situación extrema, y es ésta quien les confiere su sentido cabal. Refiriéndose al iluminado, escribe Rombach: «Él conoce las líneas de huída, que, como en una perspectiva infinita, ordenan todo lo transitorio en relación con un punto último y captan ese punto de huída innombrable incluso en su más exiguo movimiento que mueve unos hacia otros los fenómenos que se dan en primer plano». ${ }^{29}$

Pues bien, alegría es precisamente lo que experimenta este iluminado que, en el instante de su iluminación, puede captar la situación extrema inter-viniendo en todas las otras y esparciendo sobre ellas, incluso sobre las más sencillas e ínfimas, el resplandor de una luz innombrable. Al calor de esta luz todo lo vivo se vivifica y bajo su brillo se vuelve patente la íntima conexión y armonía que une a todo lo que es. La alegría, por tanto, es la experiencia de la vitalidad de

28 Cf. SA, p. 313.

$29 S A$, p. 314. 
todo lo vivo. Y como potenciar su vitalidad y poder articularla con la vitalidad de todos los demás vivientes constituye aquello hacia lo que cada vida tiende, la alegría es aquello a lo que en última instancia todo tiende. Ella es «el auténtico sentido de la vida»..$^{30}$ Ahora bien, que la alegría sea «el sentido de la vida» no significa (aunque tampoco excluye) que cada uno vaya por el mundo buscando su propio contento particular, sino que, por el contrario, implica que cada existente experimente, por lo menos en el instante de iluminación, las pequeñas, medianas y grandes circunstancias de su existencia imbricadas en el todo. Esta íntima presencia del todo en lo particular es propiamente lo que la alegría celebra. De acuerdo con ello, la alegría no es un sentimiento meramente psicológico o subjetivo, sino que es el correlato de la presencia del Todo-Vida en cada sí mismo particular como núcleo de su vitalidad y efectividad. «La alegría no es la alegría del particular en el todo, sino la alegría del todo en el particular». ${ }^{31}$ Es precisamente esta inversión la que vuelve el modelo de Rombach un modelo ontológico y hace de la alegría una gracia. Sin embargo lo dado en esta gracia no es meramente «un buen momento», sino el sentido de cada existencia en el todo, es decir, en su específica armonía con la vivificación de la vida.

Como ya hemos destacado en la concepción de la alegría de la ontología estructural se reencuentran las notas que caracterizaban formalmente la alegría en los modelos anteriores. Sin embargo, me permito llamar la atención sobre dos puntos que el análisis de Rombach lleva a primer plano y sobre los cuales los modelos previos no se pronunciaban explícitamente. En primer lugar, la afirmación de que la alegría se da en cada caso en un respectivo camino. Es posible advertir en ello el reconocimiento de que la alegría profunda acaece de múltiples maneras, porque cada sí mismo experimenta su inserción armónica en el todo de un modo en cada caso determinado. Dicho en otros términos, la alegría se da de múltiples modos porque el sentido que cada uno encuentra para su existencia es irreductible, y no es sensato pretender imponerle caminos a la gracia. De allí que haya distintas vías y formas de comprensión del fenómeno, aunque ciertamente los diferentes paradigmas guarden las mismas notas formales señaladas, sin lo cual no podríamos ver la alegría una en sus vías múltiples. En segundo lugar, desde la óptica de Rombach se evidencia claramente que la alegría no es tan sólo psicológico-subjetiva, sino constitutiva del sentido de la existencia, o, mejor dicho, constitutiva de la existencia en tanto y en cuanto todo existente tiende hacia el sentido.

A lo largo de nuestra ya extensa reconstrucción de los diferentes paradigmas de concepción de la alegría en la filosofía occidental contemporánea hemos constatado ciertas características formales comunes a todos ellos: composiblidad

30 Ibid.

31 SA, p. 315. 
o armonización vital, celebración del sentido, carácter de gracia, experiencia de una recreación o redención que restablece nuestra dignidad humana, respectividad y constitutividad. Estimo que la conjunción de las ideas de sincronía y sintonía contiene de algún modo estas características diversas y permite expresar más profundamente la naturaleza de la alegría.

\section{SinTONÍA, SINCRONÍA Y BELLEZA}

Concebida a la manera de los tres modelos analizados como celebración del sentido o plenitud de la existencia, la alegría más que a la tristeza, que siempre lo es por una causa determinada o determinable, parece oponerse a la angustia, en el sentido kierkergaardiano y heideggeraino ${ }^{32}$ del término. En efecto, la angustia nunca lo es por algo determinado, sino que es angustia por nuestro ser como pura posibilidad en tanto tal. Ahora bien, la proyección de nuestras posibilidades es aquello en función de lo cual se articula el mundo de cada existente como plexo de sentido; dicho en otros términos: es aquello que le otorga al ente en su conjunto la posibilidad de aparecer en un determinado cómo, con un cierto ser o significatividad. Precisamente en la angustia se disuelven todas las posibilidades concretas y se le revela al existente que tanto él cuanto el mundo no son nada, no tienen sentido de por sí, sino que él, como pura posibilidad en tanto que tal, tiene que hacer ser el sentido. El movimiento de ek-sistencia queda, pues, en la angustia, paralizado y el existente deja de experimentarse a sí mismo proyectado hacia una posibilidad efectiva y, por tanto, hacia un mundo articulado en función de ella, para experimentarse a sí mismo y al mundo como una nada, como una posibilidad «antes de la posibilidad». Podría decirse que, por ello mismo, en la angustia se produce una disolución de la significatividad del sentido de la existencia y, consecuentemente, de la significatividad del ente, que se transforma en lo que meramente hay, en un «habiente». El «habiente», en la medida en que no aparece iluminado por ningún proyecto-de-ser, pierde todo sentido y propiamente no es nada. Pues bien, en la alegría ocurre todo lo contrario: cada ente en el conjunto de sus relaciones con todos las demás aparece iluminado por una plenitud de sentido. Y ello porque en la alegría el existente no se proyecta meramente a una posibilidad cualquiera de su existencia, sino que lo hace hacia una posibilidad señalada, a saber, aquella que potencia y dota de significado a todas las demás. Si en la angustia quedaba paralizada toda posibilidad efectiva en función de la experiencia de la posibilidad en tanto que

32 Para un análisis detallado de la noción de angustia en el pensamiento de Kierkegaard y Heidegger, $c f$. A. Garrido-Maturano, Sobre el abismo, Buenos Aires: Adriana Hidalgo, 2006, en especial pp. 21-33 y 181-205. 
tal, en la alegría se moviliza el conjunto de las posibilidades en función de una posibilidad señalada que las consuma a todas ellas enhebrándolas en el tejido de la vida. Si la posibilidad en tanto que tal es «menos que una posibilidad», es la posibilidad «antes de la posibilidad», la posibilidad señalada es «más que una posibilidad», es la realización «de la consumación y conjugación de todas las posibilidades». Esta «posibilidad» señalada, que, como la angustia, sobreviene, es, como hemos visto, respectiva a cada existente. Sin embargo, a través de ella se observa en todos los casos una especial correlación entre el yo y el mundo, cuyas notas esenciales son dos: sintonía y sincronía. Sintonía y sincronía expresan el núcleo de aquel rasgo formal de la alegría que hemos denominado más arriba «composibilidad vital», y señalan o translucen su carácter de gracia y de acaecimiento del sentido. En tanto tal, bien podemos afirmar que sintonía y sincronía conforman la esencia última de este peculiar fenómeno que es la alegría. Veamos en qué medida.

La alegría festeja el acaecimiento de una revelación. De allí que ella, como señalaba Jankélévitch, presente siempre el carácter de una creación o inauguración, de la venida al ser de algo que no estaba dado. Pues bien, lo que se revela en la alegría o, para ser más exactos, lo que acaece (y, en tal sentido, se da o inaugura) a través de la respectiva posibilidad es siempre, en primer lugar, un modo de sintonía. Etimológicamente en la palabra sin-tonía distinguimos dos partes: la preposición griega syn que significa «con» en el sentido de «de acuerdo con» o «con la ayuda de» y el sustantivo tónos, vibración, ritmo, tono. La sin-tonía a la que nos referimos presenta dos aspectos que se dan concomitantemente y que corresponden a lo mentado por las dos partes del término compuesto de origen griego. Primeramente en la alegría al existente por vías diversas se le revela un cierto tono del mundo, es decir, le es dado percibir cómo vibra y se articula una cierta consonancia y complementación entre las distintas posibilidades vitales que aparecen en su horizonte y que se imbrican con las suyas propias (tónos). En segundo lugar, la aparición de ese tono se da de acuerdo con (syn) algo que me ha ocurrido (la posibilidad señalada) o me ha sido dado (el descubrimiento de Dios, la redención de mis faltas, la intuición de la autoconfiguración del todo, etc.) y que orienta, esto es, dota de un nuevo sentido, al conjunto de mi existencia en general. La sintonía es así una experiencia de potenciación del conjunto de mis posibilidades a la par que de integración y consonancia de esas posibilidades que ahora tengo con el conjunto de posibilidades vitales que despuntan en el horizonte. Pero si la sintonía es posible, ello se debe a que en la alegría acaece una cierta sincronía en el sentido más alto del término.

La noción de sin-cronía no significa aquí reducción de tiempos diferentes a una síntesis temporal representativa unívoca, sino con-vergencia o coordinación de temporalidades dispersas. Una convergencia que puede durar lo que un suspiro o que puede extenderse en el tiempo físico, pero que constituye siempre un 
lapso único o instante, en tanto el momento en que es experimentada la plenitud se recorta de la temporalidad extática y continua del existente y hace surgir un presente nuevo. Se trata de un presente que se distingue esencialmente del pasado que lo precede y del futuro que lo sigue y que no se halla contenido por ninguno de ellos, ni siquiera como pro-yección o retro-yección, pues la plenitud acaece de modo vivo y una plenitud que se está formando o deformando no es plenitud ninguna. Si la alegría es una gracia, y si esa gracia radica en que nos es dado experimentar el sentido como consumación armónica de posibilidades (sintonía), entonces la alegría dura lo que dura la gracia. Ese es precisamente el instante de luz, en que la sintonía se da y luego pasa, aunque su huella oriente el conjunto de nuestra vida. Ahora bien, este lapso único consiste en, como decíamos, un encuentro convergente de temporalidades. Hay alegría cuando mi ahora, el ahora en que mi vida rebosa de vitalidad, es el mismo ahora en que la vida rebosa en el otro y en lo otro que están conmigo. Y no sólo es el mismo ahora en un sentido meramente cronológico, sino en un sentido esencial, en cuanto el ahora de cada uno, para darse efectivamente como ahora de plenitud, necesita que ese ahora sea el ahora de la plenitud del otro. Dicho de otro modo, el yo necesita que ahora el otro ${ }^{33}$ sea así como el efectivamente está siendo y el otro necesita que el yo sea ahora así como él es. En la alegría esa necesidad mutua se haya satisfecha. Los ahoras se encuentran y se complementan. Ello es precisamente la sincronía. Y ello es, a mi parecer, también aquello que más fuertemente determina que la alegría sea una gracia. Porque el hecho de que mi temporalidad converja con la temporalidad del otro, que los dos aspectos que se necesitan para complementarse acaezcan concomitantemente, es precisamente aquello que simplemente sucede y que no puede ser forzado. La alegría, entonces, es sintonía, pero puede serlo, porque lo que se sintoniza acaece sincrónicamente.

A pesar de que esa sintonía y esa sincronía pueden ser experimentadas de modos diversos: ético, ontológico, religioso, etc., todos esos modos presuponen, a mi parecer, una dimensión estética. En efecto, en la sintonía y la sincronía, que determinan la esencia de la alegría, se trasluce el «sentido», entendiendo por tal una complementación armónica de posibilidades vitales consumadas, más allá de las cuales, precisamente por su carácter consumado, ya no es posible ir. Pues bien: la experiencia de esa consonancia o sintonía de posibilidades en un lapso sincrónico determinado es siempre una experiencia de la belleza: de

33 Ese otro, reitero, puede asumir formas distintas: es Dios que se me revela en el momento del martirio en que más lo necesito; es el otro que me perdona cuando más necesito ese perdón, son las conexiones de sentido entre las distintas situaciones que se me revelan cuando me proyecto a una posibilidad que las atraviesa a todas ellas, etc.; pero, en todos los casos, siempre hay una convergencia de temporalidades distintas. 
una totalidad que en un instante se da cumplida y articulada en sus detalles. La alegría es, como lo ha visto ya Spinoza, el paso «a una cierta forma de perfección» y la perfección es siempre bella. No es concebible o, en todo caso, es un contento o felicidad perversa, la que provoca un caos en que se des-componen las relaciones entre los elementos y estos se deterioran en su ser. Por el contrario, toda experiencia de alegría va acompañada de belleza, es decir, de la sensación de que todo lo que en un instante nos pasa ocurre tal y como tendría que ocurrir. Si esto es así, la alegría es esencialmente un afecto estético o, al menos, un afecto que, aún experimentado por múltiples vías, es inseparable de un trasfondo estético.

Sin embargo, a pesar de esta variedad de vías para acceder a la alegría, ¿no es acaso posible hallar una experiencia común al bienaventurado, al redimido y al iluminado, una experiencia íntimamente humana, que reúna los distintos rasgos formales del fenómeno en su unidad esencial?

Nadie como el enamorado sabe lo que es la alegría.

\section{LA VÍA ERÓTICA}

A modo ilustrativo quisiera -muy brevemente- sumar a los paradigmas analizados aún otro camino sobre el que suele sorprendernos la alegría. Se trata de un camino que, para una experiencia tan sublime como pareciera ser la que aquí hemos abordado, no exige, sin embargo, ni el martirio ni la iluminación; ni la redención ni el genio. Se trata de un camino abierto a todo hombre y entrañablemente humano. Es el camino del amor: la vía erótica.

El enamoramiento es una gracia que, como la alegría, sucede. El hombre no se enamora porque ha decidido hacerlo. No es el amor construcción de la voluntad, sino la voluntad juguete en manos de eros. Nada hemos hecho para ello, $\mathrm{y}$, en un instante, nos encontramos enamorados. Inevitable como un destino, se cierne sobre nosotros la pasión, e invade, en cuerpo y alma, nuestra existencia toda, que de ahora en más ya no es la misma. El enamorado ha renacido. El ahora en que sucede eros pone lo sido como definitivamente pasado, y hace nacer un futuro nuevo e impredecible, del que ningún pasado podría dar cuenta, simplemente porque antes ella no estaba allí. Y ese instante natalicio es, también y por excelencia, una experiencia de sincronía y de sintonía incomparables. Ella hace suceder ahora lo que yo ahora necesito que suceda y a su lado todas las cosas me son amigables. Cuando los ojos de los amantes lo miran juntos, descubren la belleza del mundo, pues donde eros está todo tiene sentido. Y es que el amor, antes que una fiesta de los sentidos, es una fiesta del sentido. Tal vez por eso sea el encuentro con la amada también un encuentro con el mundo y con la vida, y, por ello mismo, una experiencia de íntima y profunda alegría. 
En el instante en que Romeo ve por vez primera a Julieta dice de ella que su luz «les enseña a brillar a las antorchas». Y está maravillosamente dicho, pues más intenso es el brillo del mundo y más azul el cielo que lo cubre cuando los iluminan sus ojos.

Ángel E. Garrido-Maturano. Conicet - Universidad Nacional del Nordeste, Argentina.

\section{Publicaciones recientes:}

«Del postulado de sentido al sentido del postulado. Consideraciones acerca de la fenomenología de la esperanza de Bernhard Welte y su relación con el principio esperanza de Ernst Bloch», Contrastes. Revista Interdisciplinar de Filosofía, Vol. VII, 2002, pp 81-99.

«Die Erfüllung der Kunst im Schweigen. Bemerkungen zu Franz Rosenzweigs Theorie der Kunst», en: Marco M. Olivetti (comp.) Théologie negative, Biblioteca dell'Archivio di Filosofia, Padova, Cedam (Casa editrice dott. Antonio Milani), 2002, pp. 695-720.

Línea de investigación:

Fenomenología.

Dirección postal:

Avenida San Martín 218, 3541 Coronel Du Graty, Chaco, Argentina.

Dirección electrónica: hieloypuna@hotmail.com 
